\title{
Amyloid Arthropathy: A Rare Mimic of Rheumatic Disease
}

DREW BOWIE, MD; MOHAMMAD BARDI, MD, FRCPC; IMAN HEMMATI, MD, FRCPC, Division of Rheumatology, Department of Medicine, University of British Columbia, Vancouver, British Columbia, Canada. Address correspondence to Dr. D. Bowie, Royal Jubilee Hospital, Coronation Annex, 2355 Richmond Road, Victoria, British Columbia V8R 1J8, Canada. E-mail: bowie.drew@gmail.com. Providence Health Care does not require ethics board approval for case reports. A witnessed and written consent to publish this case has been obtained from the patient and is available on request. J Rheumatol 2019;46:1540-1; doi:10.3899/jrheum.181197

Amyloidosis is characterized by infiltrative deposition of amyloid into tissues ${ }^{1}$. Deposition into articular and periarticular spaces can result in amyloid arthropathy and can mimic rheumatic conditions such as gout or rheumatoid arthritis ${ }^{2}$.

A 79-year-old man with known type 2 diabetes, hypertension, chronic kidney disease (CKD) of unknown etiology, and monoclonal gammopathy of unknown significance, was admitted to hospital for worsening renal function with gross hematuria and creatinine $329 \mathrm{umol} / \mathrm{l}$ (estimated glomerular filtration rate $15 \mathrm{ml} / \mathrm{min} / 1.73 \mathrm{~m}^{2}$ ). While admitted, he fell and injured his left wrist. A computed tomography (CT) scan was negative for fracture but demonstrated unexpected extensive subchondral cysts (Figure 1) initially thought to be consistent with the punched-out lesions seen in crystal arthropathies. However, the patient had no history of gout flares, and uric acid and dual energy CT were normal. Investigations for other rheumatic conditions were negative (normal anticyclic citrullinated peptide antibodies, rheumatoid factor, C-reactive protein, and erythrocyte sedimentation rate), with otherwise normally presenting laboratory test results.

CKD evaluation demonstrated elevated $\kappa$ light chains, which led to both bone marrow and renal biopsies that demonstrated positive staining with Congo red, consistent with amyloid light-chain (AL) amyloidosis (Figure 2).

Retrospective review of the wrist imaging in the context of AL amyloidosis revealed that the CT findings were most consistent with amyloid arthropathy. The typical radiographic features include juxtaarticular soft tissue swelling, periarticular osteoporosis, and subchondral cystic lesions with well-defined sclerotic and cortical margins, as seen in this case $^{3}$. The arthropathy is progressive and commonly found in the shoulders, knees, and wrists ${ }^{4}$.
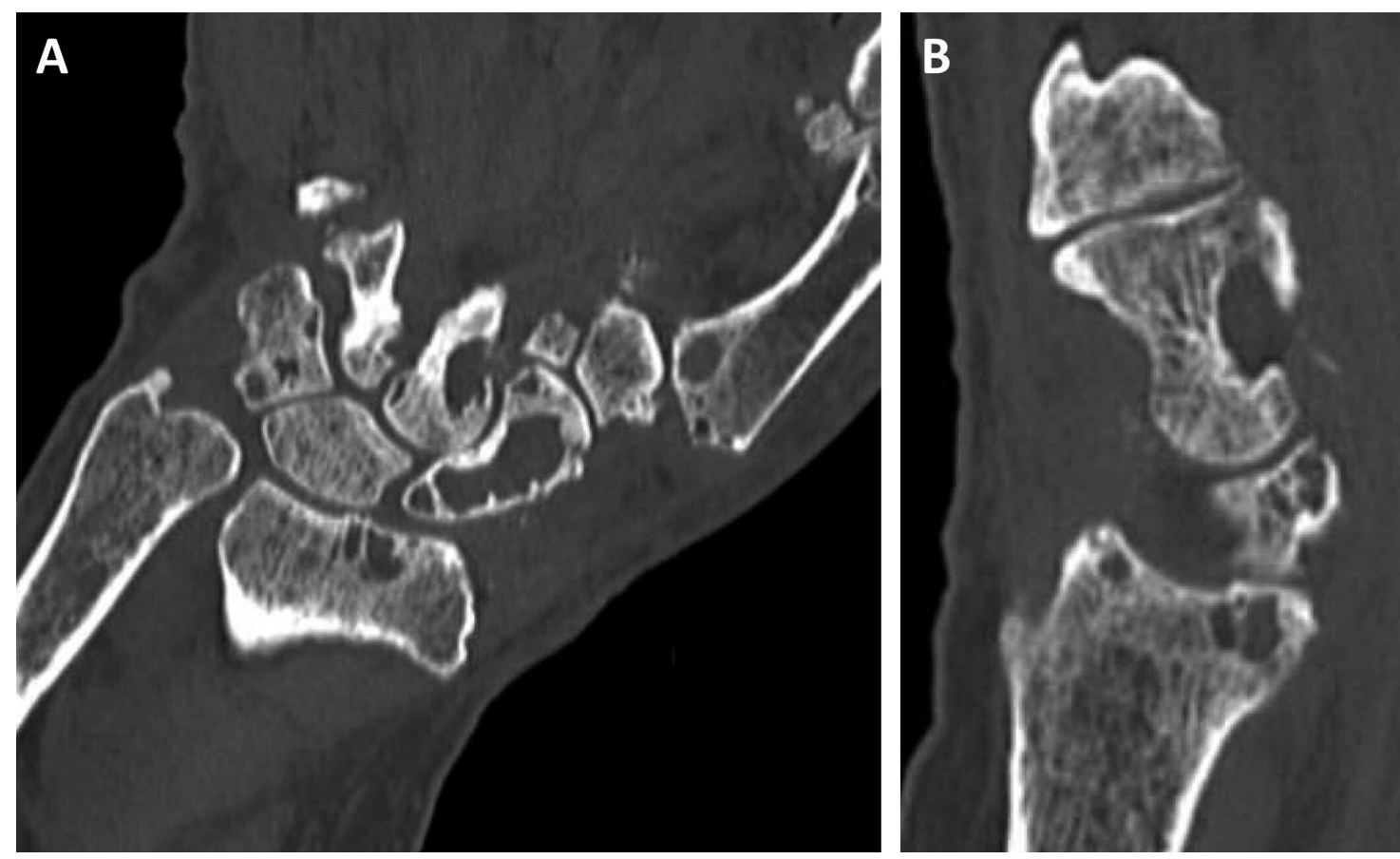

Figure 1. Computed tomography scan with (A) left wrist sagittal and (B) axial views. Extensive subchondral cyst formation throughout the carpus, distal radius, and carpometacarpal joints, most pronounced at the first carpometacarpal joint.

Personal non-commercial use only. The Journal of Rheumatology Copyright (C) 2019. All rights reserved. 


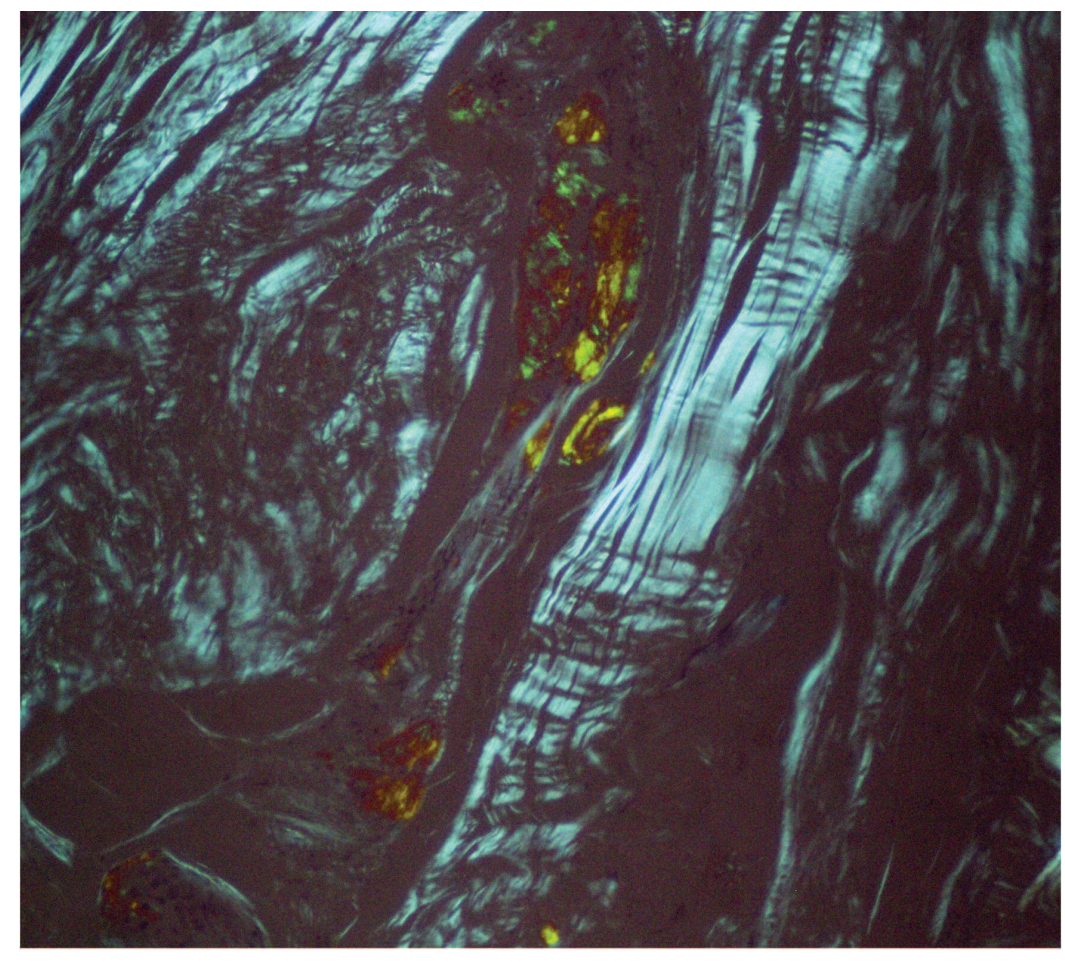

Figure 2. Congo red stain under polarizing light microscopy of the bone marrow trephine biopsy. Strongly positive apple green birefringence of amyloid deposits in a bone marrow vessel wall.

\section{REFERENCES}

1. Rambaran RN, Serpell LC. Amyloid fibrils: abnormal protein assembly. Prion 2008;2:112-7.

2. Katoh N, Tazawa KI, Ishii W, Matsuda M, Ikeda SI. Systemic AL amyloidosis mimicking rheumatoid arthritis. Intern Med 2008;47:1133-8.
3. Sheldon PJ, Forrester DM. Imaging of amyloid arthropathy. Semin Musculoskelet Radiol 2003;7:195-203.

4. M'bappé P, Grateau G. Osteo-articular manifestations of amyloidosis. Best Pract Res Clin Rheumatol 2012;26:459-75. 